\title{
Movement and Emotions
}

\author{
Sergio García-Díaz* \\ Universidad Nacional de Educación a Distancia (UNED), Spain \\ *Corresponding author: Sergio García-Díaz, Universidad Nacional de Educación a Distancia (UNED), Spain
}

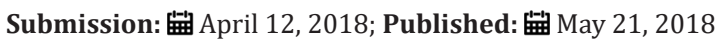

\section{Introduction}

There is no uniform conception in the literature about what an emotion is and consists of [1,2]. Consensually, essential aspects have been considered to understand emotion: the presence in emotions of physiological changes, the mobilisation of bodily actions or "tendencies of action" and the subjective experience that involves; and emotion has been approached as a result of a system of analysis and processing of information. But taking each of the elements indicated separately has not favoured knowledge of emotion being presented in an integrated manner [3]. Moreover, the investigators have been supported in their work by different a theoretical orientation, which makes it even more difficult to integrate all the knowledge. One perspective that tackles this question is the theories of Embodiment, which have their origin in the French philosopher Merleau-Ponty (1908-1961), according to which psychological processes are based on bodily states. From the perspective of Embodiment, perceiving, recognizing and interpreting an emotion in ourselves or in others requires information from bodily systems. In this way "experiencing emotional states affects somatovisceral and motoric systems" and vice versa. In other words, "bodily states have effects on how emotional information is processed" [4].

The research not only supports the intimate relationship between emotion and cognition [5], but is also argues that current neuroscience vindicates the importance of information from the body in processing emotional information [6]. Currently, the perspective of Embodiment is an appropriate framework from which to understand and consider body and somatic elements which form part of emotions. This interest is reflected in important scientific papers [7-9]. There is extensive literature linking the posture and body movement to states of emotion and affection. Riskind \& Gotay [10] found that posture affected the self reports of the mood of the participants as well as the task that they were performing. For example, the subjects who had been temporarily placed in a slumped, depressed physical posture (subject's torso was bent forward at the waist, and his chest and neck dropped downward) later appeared to develop helplessness more readily, as assessed by their lack of persistence in a standard learned helplessness task, than did subjects who had been placed in an expansive, upright posture (straight back, open shoulders, chest in a full and expansive position, head raised slightly at the chin, looking forward and slightly upward).

Duclos et al. [11] determined the influence of posture in the emotional self-reports. Subjects were induced to adopt postures characteristic of fear (seated on the edge of the chair, feet together under the chair, torso turned and leaning backwards, shoulders inwards, hands raised to the level of the mouth, arms bent at the elbow), anger (seated in a chair, the feet in contact with the floor directly under the knees, forearms and elbows on the arms of the chair, fists clenched, upper part of the body leaning slightly forwards) and sadness (lying back on the chair, the back supported on the chair back, feet under the chair, hands together in the lap). The results indicated that subjects induced to adopt emotionally expressive behaviours (postures) reported feeling the emotions they were expressing. These findings were replicated and corroborated by Flack et al. [12]. These authors observed not only that the postures relative to an emotion increased the emotional response, but that in combination with the facial expression appropriate to that emotion it produced more intense emotional responses than the posture and the facial expression separately.

More recently, Shafir et al. [13] suggest that different postures induce different emotional states: an upright position, pride; a slouching position, sadness; and an expansive position, power. Likewise, they suggest that deliberate control of motor behaviour could regulate the feelings. Thus, the motor execution of movements of happiness, jumping for example, significantly increases positive affect; the execution of movements of fear, protecting oneself for example, significantly increase negative affect; the execution of sad movements, bowing the head for example, increases sad feelings; the execution of emotionally neutral movement's increases neutral feelings. Therefore, engaging in movements associated with a certain emotion would enhance that emotion and/or the corresponding valence. The influence of the way of walking on mood was also studied. Michalak et al. [4] studied the effects of the sad and depressive mood on gait and the results of their investigation show that individuals with dysphoric mood are characterised by a specific pattern of walking, that is to say, "reduced walking speed, arm swing, vertical movement of the head, stronger lateral body 
sway, and a slumped posture" (p.585). Previous studies already suggested that depressed patients evidence reduced gait velocity, stride length, increased standing phase and gait cycle duration [14].

In relation to body movement the effect on the emotions of head movements and the movements of extending/flexing the arms was also analysed. Cacioppo et al. [15] found that the isometric flexed arm (associated with approximation, for example, putting food in the mouth) and arm extension (associated with rejection) affect the cognitive processing of the stimuli presented, making the subjects evaluate neutral stimuli more positively during the flexing of the arm than during the extension of the arm. Chen \& Bargh [16] observed that for the participants in their study it was simpler to flex the arms after dealing with positive stimuli and to extend them after observing negative images than the reverse. And Wiers et al. [17] showed that the movements of flexing and extending the arm serve to modify cognitive bias in alcoholic patients, so that patients' approach bias changed into an avoidance bias for alcohol. Finally, in relation to the effect of head movements on the emotional state, a study by Rahona et al. [18] suggests that head movements influence emotional regulation in people with dysphoria. According to this study, the act of assenting counteracts the effect of the dysphoria in mood regulation, improving the regulatory ability of participants with high levels of dysphoria. The results of this study suggest that the head movements might play a moderating role in the relation between the levels of dysphoria and the mood regulation ability of the individuals.

\section{Conclusion}

There seems to be a considerable amount of evidence of the relation between body movement and emotional state. A certain emotional state leads to a type of movement (for example, sadness to reduced gait velocity). And, vice versa, a certain movement can facilitate an emotional state (for example, jumping and happiness). Avoiding certain movements would also influence the emotional state whereas, on the other hand, trying to avoid emotional states would have consequences on body movement. In fact, one of the effects of emotional suppression is a decrease of the body movement indicators, which are registered through the physiological measure of somatic activity [19]. Emotional suppression is a type of emotional regulation that is defined as "conscious inhibition of one's own emotional expressive behaviour while emotionally aroused" [19]. And emotional regulation "consists of the extrinsic and intrinsic processes responsible for monitoring, evaluating, and modifying emotional reactions, especially their intensive and temporal features, to accomplish one's goals" [20].

Thus body movement, in any of its possible modalities (sport, physical exercise, dancing, etc.), could be a valid tool for emotional regulation. Body movement not only facilitates emotional expression but also makes it possible to redirect the emotions. The intention is not to use movement as a way of avoiding some painful emotions, since sometimes feeling these emotions is psychologically healthy because it permits greater congruence with the true self (for example, experiencing sadness upon the death of a loved one instead of avoiding it) [21-23]. Body movements are a way of modifying the emotional state. However, before modifying it, it must be understood, since the emotions provide people with information about what is happening to them and about how to experience what is happening.

\section{References}

1. Cabanac M (2002) What is emotion? Behav Processes 60(2): 69-83.

2. Kagan J (2007) What is emotion? History, measures, and meanings. New Haven, Conn, Yale University Press, USA.

3. Fernández-Abascal EG, Jiménez-Sánchez MP (2010) Psicología de la emoción [Psychology of emotion]. In Fernández-Abascal EG, García B, Jiménez MP, Martín MD, Domínguez FJ (Eds.). Psicología de la Emoción [Psychology of emotion]. Editorial Universitaria Ramón Areces, Madrid, Spain.

4. Michalak J, Troje NF, Fischer J, Vollmar P, Heidenreich T, et al. (2009) Embodiment of sadness and depression-gait patterns associated with dysphoric mood. Psychosomatic Medicine 71(5): 580-587.

5. Lewis M, Haviland-Jones JM, Barrett LF (2008) Handbook of Emotions. Guilford Press, New York, USA.

6. Damasio A (1994) Descartes' error: emotion, reason, and the human brain. Avon Books, New York, USA.

7. Niedenthal PM, Barsalou F, Ric F, Krauth-Gruber S (2005) Embodiment in the acquisition and use of emotion knowledge. In: Barrett LF, Niedenthal PM, Winkielman P (Eds.), Emotion and consciousness. Guilford Press, New York, USA.

8. Price TF, Peterson CK, Harmon J (2012) The emotive neuroscience of embodiment. Motivation and Emotion 36(1): 27-37.

9. Winkielman P, Niedenthal P, Oberman LM (2009) Embodied perspective on emotion-cognition interactions. In: Pineda J (Ed.), Mirror neuron systems, Humana Press, New York, USA, pp. 235-257.

10. Riskind JH, Gotay CC (1982) Physical posture: Could it have regulatory or feedback effects on motivation and emotion? Motivation and Emotion 6(3): 273-298.

11. Duclos SE, Laird JD, Schneider E, Sexter M, Stern L, et al. (1989) Emotion specific effects of facial expressions and postures on emotional experience. Journal of Personality and Social Psychology 57(1): 100-108.

12. Flack WF, Laird JD, Cavallaro LA (1999) Separate and combined effects of facial expressions and bodily postures on emotional feelings. European Journal of Social Psychology, 29(2-3): 203-217.

13. Shafir T, Taylor SF, Atkinson AP, Langenecker SA, Zubieta J K (2013) Emotion regulation through execution, observation, and imagery of emotional movements. Brain Cogn 82(2): 219-227.

14. Wendorff T, Linnemann M, Lemke MR (2002) Lokomotion und depression [Locomotion and depression]. Fortschritte in Neurologischer Psychiatrie 70: 289-296.

15. Cacioppo JT, Priester JR, Berntson GG (1993) Rudimentary determinants of attitudes II: Arm flexion and extension have differential effects on attitudes. J Pers Soc Psychol 65(1): 5-17.

16. Chen M, Bargh JA (1999) Consequences of automatic evaluation: Immediate behavioral predispositions to approach or avoid the stimulus. Personality and Social Psychology Bulletin 25(2): 215-224.

17. Wiers RW, Eberl C, Rinck M, Becker ES, Lindenmeyer J (2011) Retraining automatic action tendencies changes alcoholic patients' approach bias for alcohol and improves treatment outcome. Psychol Sci 22(4): 490497. 
18. Rahona JJ, Ruiz Fernández S, Rolke B, Vázquez C, Hervás G (2014) Overt head movements moderate the effect of depressive symptoms on mood regulation. Cogn Emot 28(7): 1328-1337.

19. Gross JJ, Levenson RW (1993) Emotional suppression: physiology, self-report, and expressive behavior. J Pers Soc Psychol 64(6): 970-986.

20. Thompson RA (1994) Emotion regulation: A theme in search of definition. Monogr Soc Res Child Dev 59(2-3): 25-52.

21. Diener E, Sandvik E, Pavot W (1991) Happiness is the frequency, not the intensity, of positive versus negative affect. In: Strack F, Argyle M, Schwarz N (Eds.), Subjective well-being: An interdisciplinary perspective Oxford: Pergamon Press, USA,
22. Waterman AS (1993) Two conceptions of happiness: Contrasts of personal expressiveness (eudaimonia) and hedonic enjoyment. Journal of Personality and Social Psychology 64(4) 678-691.

23. Ryan RM, Deci EL (2001) On happiness and human potentials: A review of research on hedonic and eudaimonic well-being. Annu Rev Psychol 52(1): 141-166.

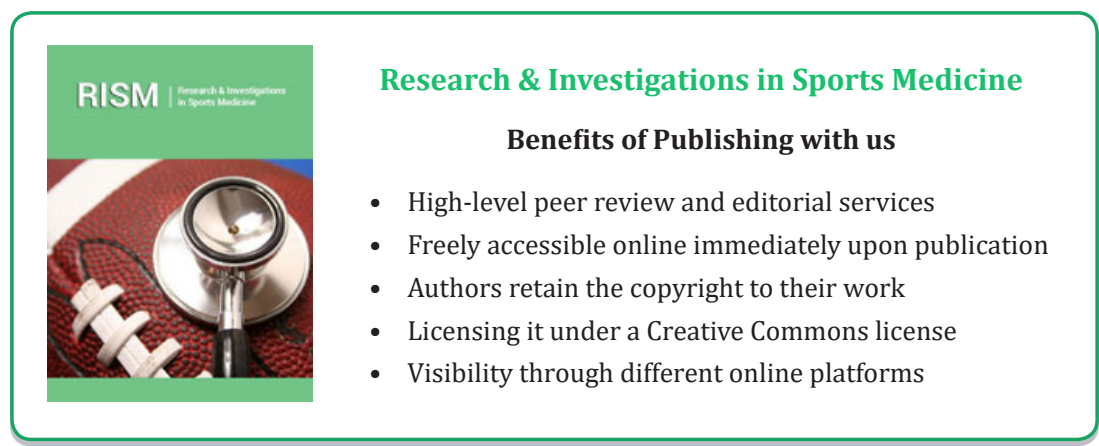

